\title{
Philosophiques
}

\section{Anne Cauquelin, La mort des philosophes et autres contes, Paris, Presses Universitaires de France, 1992, 128 pages.}

\section{Fernand-Luc Bergeron}

Volume 23, numéro 1, printemps 1996

Critères esthétiques et métamorphoses du beau

URI : https://id.erudit.org/iderudit/027378ar

DOI : https://doi.org/10.7202/027378ar

Aller au sommaire du numéro

Éditeur(s)

Société de philosophie du Québec

ISSN

0316-2923 (imprimé)

1492-1391 (numérique)

Découvrir la revue

Citer ce compte rendu

Bergeron, F.-L. (1996). Compte rendu de [Anne Cauquelin, La mort des philosophes et autres contes, Paris, Presses Universitaires de France, 1992, 128 pages.] Philosophiques, 23(1), 173-174. https://doi.org/10.7202/027378ar d'utilisation que vous pouvez consulter en ligne.

https://apropos.erudit.org/fr/usagers/politique-dutilisation/ 


\section{COMPTES RENDUS}

Anne Cauquelin, La mort des philosophes et autres contes, Paris, Presses Universitaires de France, 1992, 128 pages.

L'histoire retient de la vie de l'artiste le moment de sa naissance alors qu'elle retient de la vie du philosophe le moment de sa mort. À partir de cette constatation, Anne Cauquelin s'intéresse aux différentes figures de la mort des philosophes données par la doxa Dans sa dimension historique, le livre s'attache surtout à la période hellénique, mais il fait également référence à des auteurs plus récents. La problématique de l'auteur suit deux parcours : d'une part, la mort des philosophes : d'autre part, le rôle de la doxa dans la transmission de la légende. Le but de l'auteur est de réintégrer la doxa en philosophie, implicitement, par l'entremise de la mort des philosophes.

À travers les différentes figures de la mort des philosophes c'est bien de la doxa que l'auteur veut nous entretenir. Celle-ci nous rappelle que la notion de doxa est une constante dans son travail (p. 9, note 1). La thèse d'Anne Cauquelin est que la doxa (rumeur, opinion) contribue à la construction du personnage "philosophe". Ainsi deux questions sont au centre de l'ouvrage: comment la doxa constitue la figure du philosophe et quelle sera le lieu qu'elle privilégiera. Notre propos ne sera pas de reprendre toutes les variantes de la mort des philosophes, car nous ne pourrions pas rendre justice à la dimension satirique du livre. Nous nous limiterons donc a l'analyse de la problématique "doxalogique".

La doxa se définit comme rumeur, fable et on-dit. L'auteur la qualifie sous divers vocables: travailleuse, inlassable, laborieuse et imaginative. Mais plus important encore, elle est le lieu de la mémoire. Son but consiste à aller au-delà des apparences. C'est la doxa qui recueille les informations nécessaires pour la construction de ce chàteau d'illusion de la mort des philosophes. On se retrouve ainsi devant une dichotomie entre les notions de vérité et de mensonge, c'est-àdire devant une barrière entre les théoriciens et la pensée du peuple. L'opinion, contrairement à la vérité, laisse place à l'interprétation et à l'indétermination. Nous pouvons qualifier la doxa d'artiste, elle sera manipulatrice, justicière et moraliste. Nous sommes en face du juge suprême, mère de la connaissance.

La doxa a la tâche de nous faire découvrir les philosophes dans leur historicité. Elle recherche le côté obscur des choses, la face cachée de la lumière. Mais il reste le moment de l'indetermination dans les différentes versions de la mort des philosophes. Par exemple, on ne peut faire mourir une figure légendaire comme Aristote d'une seule mort, car on ne rendrait pas justice à sa grandeur. Pour la doxa il faut lui faire l'honneur de l'ambiguïté.

La rumeur nous entraine toujours sur des terrains vagues, sinon troublants et meurtriers. Elle fait mourir de façon absurde ceux dont elle veut ternir la réputation. La doxa, comme un remède, peut ètre bénéfique pour la santé, mais elle peut tout aussi bien devenir dévastatrice. Comme lorsque la rumeur s'empare de l'erreur pour détruire la raison. C'est elle qui demeure la reine de 
la version définitive et qui maintient l'emprise sur la signification autobiographique et philosophique du philosophe. Les philosophes feront appel aux spectres pour connaitre leur destineee. Mais la doxa est elle-mème un songe. Le rêve est un adversaire qu'elle ne peut se permettre de reconnaitre.

L'opinion permet une pluralité d'interprétations sur la mort des philosophes antiques. Avec la venue de la profession d'historien et de son intérèt pour la vérité historique, l'opinion n'a plus cette liberté d'autrefois. Elle devra mettre en place tout un jeu de mise en scène pour parvenir à instaurer le modèle "pur " de la mort du philosophe. Vis-à-vis du vide, du silence, la doxa aura le rêflexe de remplir l'abime. Pour celui qui se moque de l'humanité elle n'aura nulle pitié.

Nous pouvons conclure en affirmant que la lecture du livre d'Anne Cauquelin s'avère à la fois très agréable et satirique. Nous aurions cependant encouragé l'auteur à ètendre son investigation aux philosophes médiévaux. En outre, comment a-t-elle pu oublier de mentionner la mort d'Hypatie, une des seules femmes de l'Antiquité sur qui la doxa maintient encore l'ambiguïté ?

Fernand-Luc Bergeron

Chicoutimi 